\title{
Processes on Uncontrolled Aerodromes and Safety Indicators Part II
}

\author{
Vladimír Plos \\ Laboratory of Aviation Safety and Security, \\ Department of Air Transport, Faculty of Transportation \\ Sciences, Czech Technical University in Prague \\ Horská 3, Prague 2, 128 03, Czech Republic \\ e-mail: plosvlad@fd.cvut.cz \\ Karel Jeřábek \\ Department of Air Transport, \\ Department of Air Transport, Faculty of Transportation \\ Sciences, Czech Technical University in Prague \\ Horská 3, Prague 2, 128 03, Czech Republic
}

\author{
Jakub Kraus \\ ATM Systems Laboratory, \\ Department of Air Transport, Faculty of Transportation \\ Sciences, Czech Technical University in Prague \\ Horská 3, Praha 2, 128 03, Czech Republic \\ e-mail: kraus@fd.cvut.cz \\ Peter Vittek \\ Laboratory of Aviation Safety and Security, \\ Department of Air Transport, Faculty of Transportation \\ Sciences, Czech Technical University in Prague \\ Horská 3, Praha 2, 128 03, Czech Republic
}

\begin{abstract}
This article follows on the Part I, where the basic processes on uncontrolled aerodromes were introduced. The uncontrolled aerodromes face with the growing traffic and from that result the higher workload on AFIS officer. This means a higher potential for dangerous situations.

The article describes some models of sub-processes and creates several safety indicators related to the operation at uncontrolled aerodromes. Thanks to monitoring and evaluation of safety indicators can be adopted targeted safety measures and thus increase safety on small uncontrolled aerodromes.
\end{abstract}

Keywords - safety, aerodrome procedures, aviation safety, process model, uncontrolled aerodrome

\section{INTRODUCTION}

The most important process at uncontrolled aerodromes is a process of communication between AFIS/service which provides information (officer) and pilot of the airplane who wants to take off/land or fly through ATZ. During this processes, there is the biggest potential to make mistakes. These processes are further divided into several subprocesses, which are described below.

\section{THE PROCESSES OF COMMUNICATION BETWEEN THE OFFICER AND THE PILOT}

The initial process of communication is the communication between officer and the crew of aircraft which joined to the traffic on the aerodrome. During this process, there is an important step that the crew informs about the position on aerodrome and further intensions. Thanks to this process, officer gets the situation awareness. Officer informs about actual traffic on aerodrome, current weather and other important information. This is followed by the process of communication during the runway line-up - model of this process is on figure 1. The critical challenge in this process is the announcement of the intent of further action. During the observation on aerodromes, there were often situations, when pilot began taxiing without informing the officer. The model describes situation on aerodromes, where is necessary to taxi on runway before take-off. 


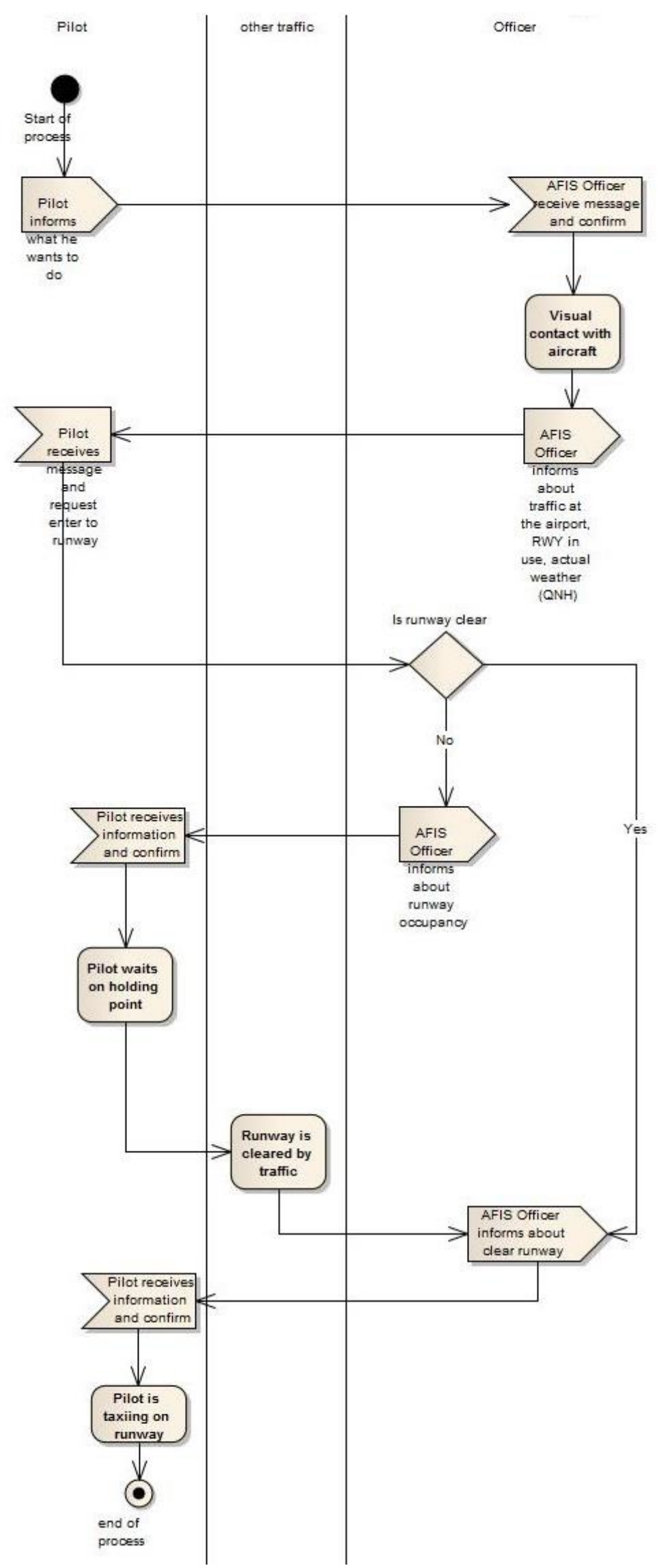

Figure 1. Communication before runway line-up 
After this process there is a line-up. If the pilot announced the intention to take-off, the process of communication on the line-up position between the crew and officer follows.

The primary impulse in this process is the pilot's announcement that he wants to take-off. The officer responds with the announcement about the state of the runway - whether it is clear or occupied. Next procedures are shown in Figure 2. A critical procedure in terms of observations at aerodromes was announcement of the intention to take-off. If pilot takes-off without informing the officer, it could result in dangerous situation. Runway could be occupied by another taxiing or taking-off aircraft because officer could approve taxiing or taking-off of another aircraft.

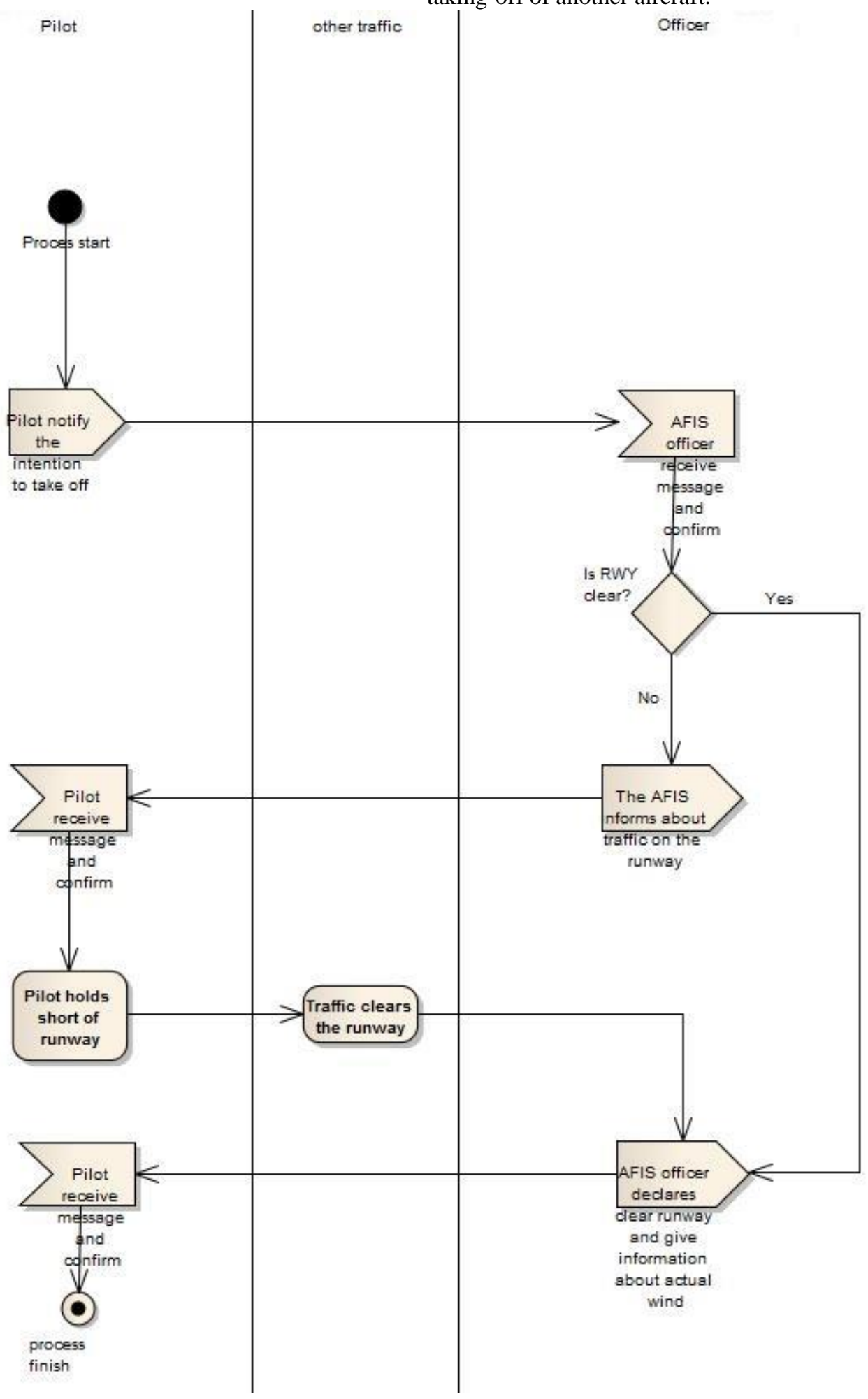

Figure 2. Communication on line-up position 
After that communication, the process of taking-off occurs. After the take-off, pilot is on the aerodrome circuit, where are two options. First one is that pilot leaves the circuit and flies away from the ATZ. The second one is flying on the circuit e.g. due to training. When flying away from the ATZ, pilot informs about the intentions with the estimated time of return (if the pilot expect landing on the aerodrome of departure) and officer informs about regional QNH and other important informations about surrounding traffic. Pilot receives this information, acknowledge and leave the ATZ. In the situation, when pilot remains on the aerodrome circuit, there is a process of communication described in figure 3 . Here it is important to establish visual contact with the aircraft for accurate information to surrounding traffic and giving the number to land. During observing on aerodromes there were several mistakes and misunderstood between the crew and officer in time of dense traffic.

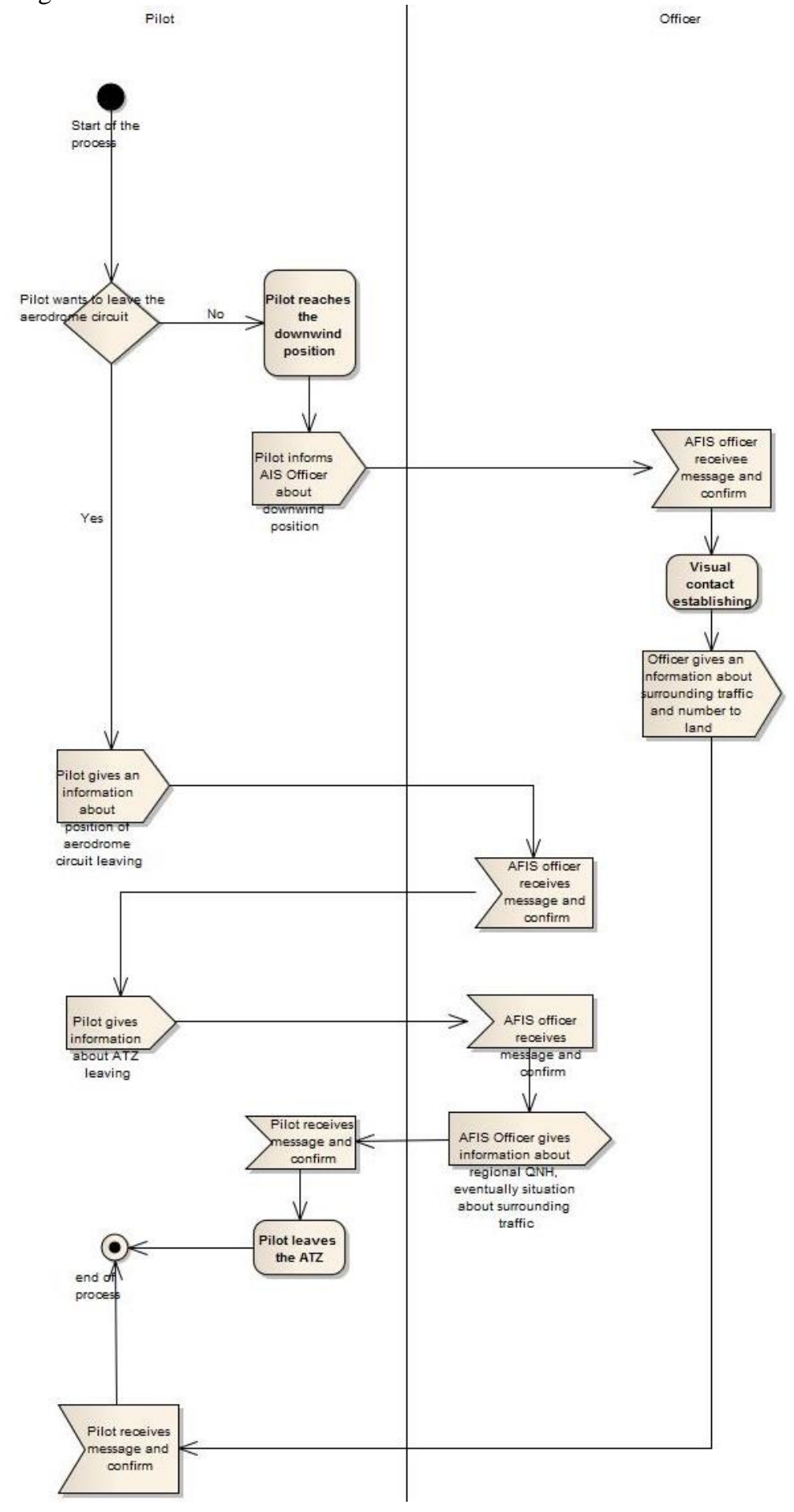

Figure 3. Communication on aerodrome circuit 
Another important process is communication with the aircraft, when the pilot should report position on final. This situation occurs in two ways. The first one is flight on the circuit - see previous case, and the second one is the arrival from airspace and joining to aerodrome circuit.

During arrival from surrounding airspace, there is a critical procedure of informing about current position of the airplane. During this act, crew must provide accurate information about their position, because the officer does not have another chance to verify the information. Officer's situational awareness depends on the accuracy of the information. After reaching the aerodrome circuit, visual contact is established. During this procedure sometime occur longer or shorter delays caused by the inaccurate location information and the search for the aircraft in the whole area around the aerodrome. In one case, there was an event, when airplane flew through ATZ without any previous contact. Situations with the potential impact on safety might arise from these events. The process of arriving from the surrounding airspace is shown in the following model in Figure 4.

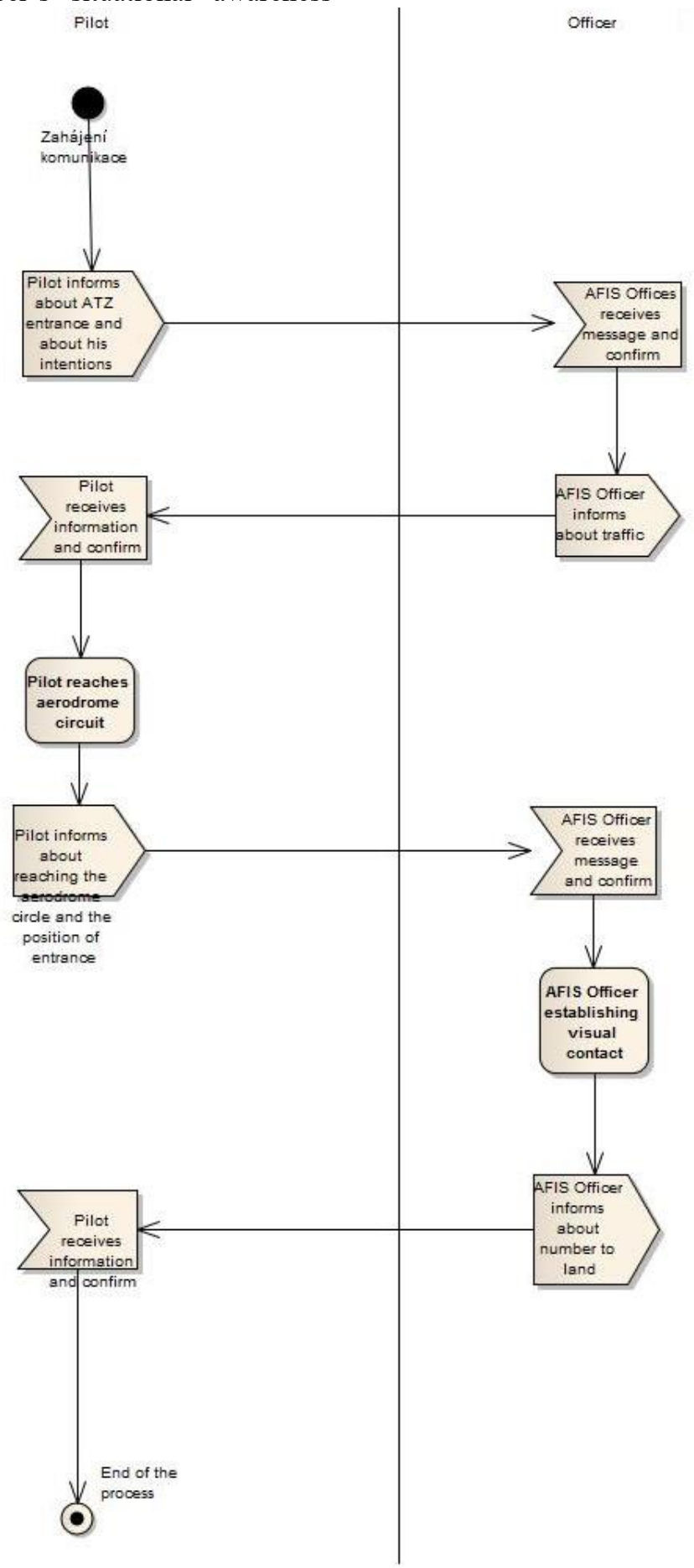

Figure 4. Communication during arrival from surrounding airspace 
After flight on aerodrome circuit, the process of communication on final follows. During this process it is important to inform correctly about number to land and it is necessary to hold accurate spacing between aircraft by the crews. This process is also affecting by process of taking-off or lining-up the runway. During this process it is again necessary to give clear and correct information about position due to situation awareness of officer. The process is illustrated on figure 5. When observing this process, incorrect informing about position often occurred in real situation e.g. the crew informs about position on final when the aircraft is still in base position.

After this process, follow full landing, or Touch-and-Go procedure.

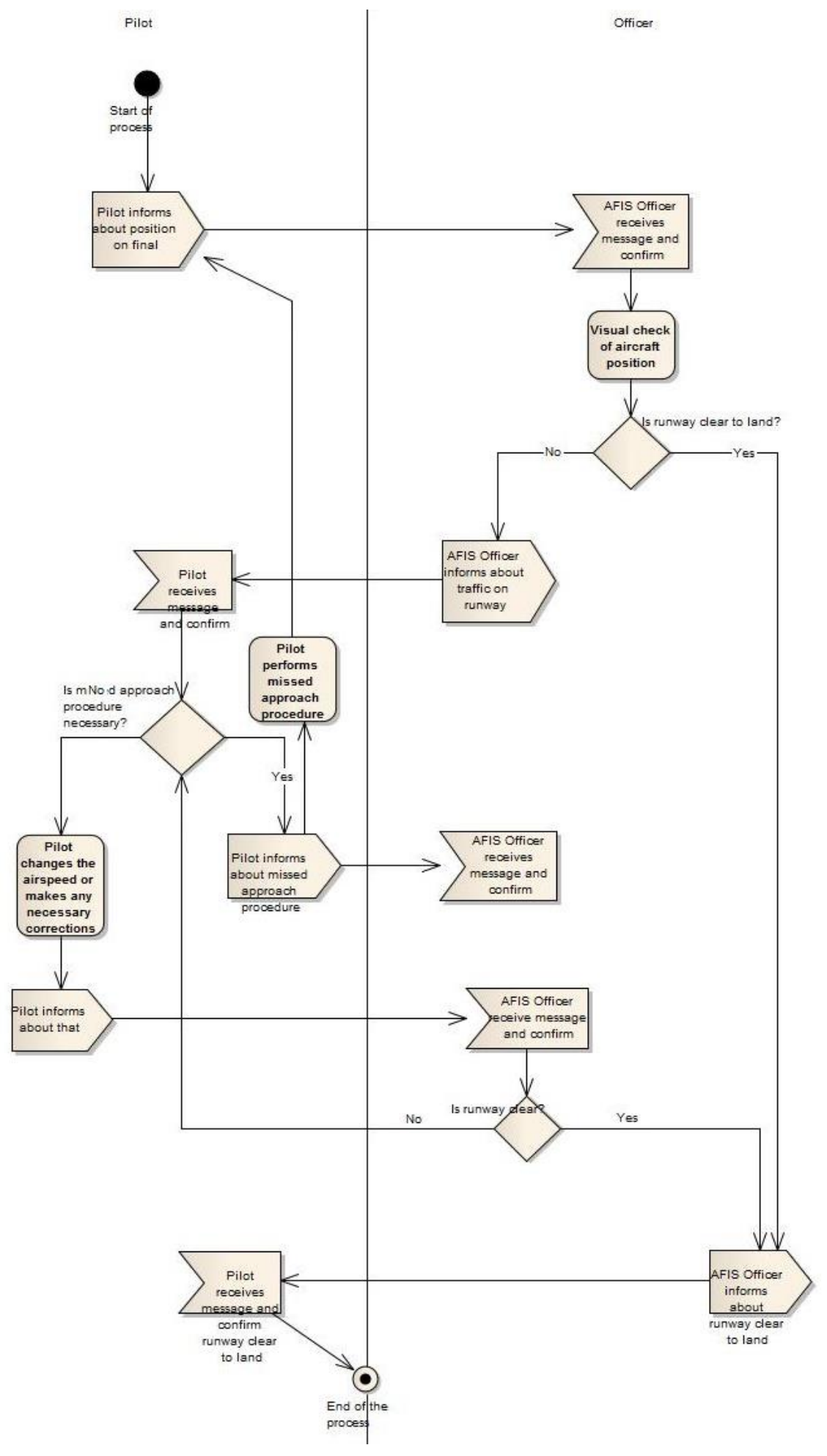

Figure 5. Communication on final 


\section{SAFETY INDICATORS PROPOSAL}

In all the models described in part I and part II could be found potential risk operations, which result in the emergency situation. If we focus on these operations, and we measure their occurrence, we would come to the use of safety indicators. From the observations could be as the main challenge seen the establishing of visual contact. This activity was often difficult due to not fully correct information about aircrafts positions which reported their crews. The risk of this situation increases with the closeness of the aircraft to the runway threshold. If the aircraft reports wrong its position between the first and second turn of the aerodrome circuit, it does not mean a problem as big as when the crew reports the wrong location between the third and fourth turn where traffic is denser due to aircraft returning from "space" and can thus lead to giving wrong number to land and subsequent realizations of "Go-Around" procedures.

For the improvement of safety on small uncontrolled aerodromes is therefore necessary to focus on the process of communication regarding the position of the aircraft and the subsequent establishment of visual contact. In these cases, it is appropriate to introduce a system of reactive indicators that will track the occurrence of these events. For starters, the reactive safety indicators system could include the number of "Go-Around" procedures, the number of false position reports, and wrong information about number to land. These basic indicators related to the observed riskiest activities could be the start of risk management for aerodromes. The values that we follow for the measurement of the indicators are always necessary to recalculate to the base level to be comparable in several aerodromes. This base level could be set to 100 movements considering the size of traffic in small uncontrolled aerodromes. Thus we get a credible basis for statistics and evaluation of operational safety at small uncontrolled aerodromes.

\section{CONCLUSION}

From the above it is clear that the introduction of safety indicators at small aerodromes with uncontrolled traffic would increase operating safety thanks to recording events with a potential of dangerous situation and their re-evaluation and also corrective measures that would be precisely targeted to the problem area. To the proposed system of reactive indicators should be added a proactive system of monitoring the safety culture; the willingness of staff perceive safety as part of all processes that are executed in the context of their activities in the field of small aviation.

\section{ACKNOWLEDGMENT}

This paper was supported by the Grant Agency of the Czech Technical University in Prague, grant No. SGS13/090/OHK2/1T/16.

\section{REFERENCES}

[1] Česká republika. Předpis L11. Praha, 2013. Dostupné z: <http://lis.rlp.cz/predpisy/predpisy/dokumenty/L/L11/data/print/L11_cely.pdf >

[2] ØIEN, K., I.B. UTNE a I.A. HERRERA. Building Safety indicators: Part 1 - Theoretical foundation. Safety Science. 2011, vol. 49, issue 2, p. 148
161. DOI: 10.1016/j.ssci.2010.05.012. available at: <http://linkinghub.elsevier.com/retrieve/pii/S0925753510001335>.

[3] Eurocontrol AFIS manual. [online]. Eurocontrol. Available at 〈http://www.skybrary.aero/bookshelf/books/1446.pdf>

[4] Plos, V. - Capoušek, L.: Processes on Uncontroled Aerodromes and Safety Indicators Part I. MAD - Magazine of Aviation Development [online]. 2013, vol. 1, no. 5, p. 11-15. Internet: http://mad.fd.cvut.cz/issues/5/03_Plos_Capousek.pdf. ISSN 1805-7578. 